\title{
A INFORMAÇÃO ARQUIVÍSTICA NO PROCESSO DE TOMADA DE DECISÃO EM ORGANIZAÇÕES UNIVERSITÁRIAS: PROCEDIMENTOS METODOLÓGICOS
}

\author{
Nádina Aparecida Moreno
}

\begin{abstract}
Resumo
Relata a trajetória metodológica percorrida na tese de doutorado intitulada "a informação arquivística no processo de tomada de decisão em organizações universitárias". A abordagem selecionada foi qualitativa, adotando-se o estudo de caso, a análise documental e a técnica do incidente crítico de Flanagan (1973). O estudo de caso foi efetuado junto aos Conselhos Superiores da Universidade Estadual de Londrina, Estado do Paraná. A análise documental efetivou-se em um determinado processo da Instituição, de acordo com os critérios de intencionalidade elaborados pela pesquisadora. As entrevistas com os sujeitos do estudo foram semi-estruturadas e utilizou-se a análise de conteúdo de Bardin (c1977). Os procedimentos metodológicos selecionados na pesquisa foram adequados e permitiram atingir os objetivos propostos.
\end{abstract}

\section{Palavras-Chave}

Informação Arquivística; Organizações Universitárias; Procedimentos Metodológicos

\section{INTRODUÇÃO}

O artigo registra o caminho percorrido nos procedimentos metodológicos de uma tese de doutorado que teve por objetivo geral investigar o papel da informação ar- quivística no processo de tomada de decisão em universidades públicas, e por objetivos específicos: identificar a natureza das informações e os tipos das fontes de informação utilizadas no processo de tomada de decisão dos gestores universitários; a- 
veriguar os meios utilizados pelos decisores para obterem as informações necessárias à tomada de decisões; reconhecer os elementos facilitadores e dificultadores dos administradores universitários na obtenção/recuperação das informações necessárias ao processo decisório, detectar se a forma de organização dos documentos de arquivo interfere no processo de tomada de decisão dos gestores universitários.

Para a consecução desses objetivos utilizou-se a pesquisa qualitativa adotandose o estudo de caso, a análise documental e a técnica do incidente crítico.

O estudo de caso foi efetuado na Universidade Estadual de Londrina, sediada na cidade de Londrina, Estado do Paraná, onde se detectavam algumas limitações na sua estrutura organizacional (hierarquização piramidal) que interferem no processo de tomada de decisão: a existência de fragmentação do processo de trabalho com grande número de instâncias decisórias; um excesso de massa documental produzida e acumulada em decorrência das atividades desenvolvidas pelos seus diversos órgãos, contendo um volume informacional expressivo tanto para a comunidade universitária, como para a comunidade local, regional e nacional, em conseqüência dos avanços do ensino, da pesquisa, da extensão.

As informações permeiam e se constituem em matéria prima indispensável às decisões dos gestores universitários. Mas, por outro lado, indaga-se qual a natureza das informações e das fontes de informações que são utilizadas no processo de tomada de decisão pelos gestores de universidades públicas? Considerando-se que o volume de documentos produzidos e recebidos pela Instituição é muito grande e que não existe a gestão documental dos mesmos, será que a forma como esses documentos estão organizados interfere no processo decisório?

Analisando essas questões a pesquisa elencou, baseado na literatura da área quatro pressupostos que nortearam o estudo: 1) A informação arquivística é a informação mais utilizada pelos gestores universitários na tomada de decisão; 2) Os documentos de arquivo encontram-se de alguma maneira organizados nas unidades e subunidades da Universidade Estadual de Londrina; 3) Os contatos pessoais são menos utilizados pelos conselheiros na obtenção/recuperação de informações para a tomada de decisão, 4) A ausência de uma política de gestão documental e da informação arquivística é um dos elementos que mais dificulta o processo decisório, em relação à obtenção/recuperação das informações.

Ciente de que o caminho a ser trilhado no que tange a metodologia é bastante complexo, o artigo apresenta um arquétipo para a socialização dessa experiência a 
pesquisadores da área, sempre lembrando que "toda pesquisa cria para si um método adequado, uma lógica própria, cuja generalidade e universalidade consiste apenas em ser "conforme ao fim"' (GRAMSCl, 1999, p. 234-35).

\section{PESQUISA QUALITATIVA: ESTUDO DE CASO, ANÁLISE DOCUMENTAL E TÉCNICA DO INCIDENTE CRÍTICO}

Para obter informações de pessoas que participam diretamente dos fatos, para o estudo de um acontecimento específico com maior profundidade, que possibilite a interação entre investigador e sujeitos da pesquisa a pesquisa, qualitativa é a abordagem que pode permitir o sucesso da pesquisa. O estudo de caso, a análise documental e a técnica do incidente crítico, são recursos metodológicos indispensáveis para a pesquisa qualitativa.

A adoção de várias técnicas é interessante, pois permite a triangulação dos dados. Por triangulação, entende-se o emprego de técnicas de pesquisa diferentes de coleta dos mesmos dados e comparação dos resultados.

A abordagem qualitativa justifica-se, de acordo com Liebscher (1998), quando o fenômeno em estudo é complexo, de natureza social e não tende à quantificação. Para aprender métodos qualitativos, é preciso aprender a observar, registrar e anali- sar interações reais entre pessoas, e entre pessoas e sistemas.

A pesquisa qualitativa desenvolve-se em uma situação natural, é rica em dados descritivos, possui um plano flexível e focaliza a realidade de forma complexa e num determinado contexto. Significa dizer que o ambiente natural é a fonte direta para a coleta de dados, e o pesquisador é o instrumento chave.

As características comuns aos estudos de caráter qualitativo, na opinião de Bogdan e Birten (1982); Straus e Corbin (1990); Minayo (1997), Denzin e Lincoln (1998) podem ser resumidas em:

a) a pesquisa qualitativa tem 0 ambiente natural como fonte direta dos dados e o pesquisador como instrumento chave;

b) a pesquisa qualitativa é descritiva;

c) os pesquisadores qualitativos estão preocupados com o processo e não simplesmente com os resultados e o produto;

d) os pesquisadores qualitativos tendem a analisar seus dados indutivamente;

e) o significado é a preocupação essencial na abordagem qualitativa;

f) o estudo dos fenômenos sociais tem como foco os significados dos sujeitos que os constroem; parte-se do princípio de que o estudo precisa também ser analisado na perspectiva dos sujeitos. Os dados 
são coletados, de preferência, nos contextos onde os fenômenos são construídos;

g) a análise dos dados é desenvolvida, de preferência, no decorrer do processo de levantamento de dados.

Em relação ao método de estudo de caso, é interessante ressaltar que ele é utilizado para obter conhecimento em profundidade de uma situação, mostrando o significado dos envolvidos, cujo interesse reside no processo.

No entendimento de Ludke e André (1986), o estudo de caso, seja ele simples e específico ou complexo e abstrato, é sempre bem delimitado e seus contornos são claramente definidos no desenrolar do estudo. O estudo de caso é escolhido quando se quer pesquisar algo singular, que tenha valor em si mesmo.

Entre outras características básicas do estudo de caso, Benbasat, Goldstein e Mead (1987) e Trauth e Oconnor (2004) apontam:

- o fenômeno é observado em seu ambiente natural;

- os dados são coletados por diversos meios;

- uma ou mais entidades (pessoa, grupo ou organização) são examinadas;

- a complexidade da unidade é estudada intensamente;
- não são utilizados controles experimentais ou manipulações;

- o pesquisador não precisa especificar previamente o conjunto de variáveis dependentes e independentes;

- os resultados dependem fortemente do poder de integração do pesquisador;

- podem ser feitas mudanças na seleção do caso ou dos métodos de coleta de dados à medida que o pesquisador desenvolve novas hipóteses,

- a pesquisa está envolvida com questões "como" e "por que" ao invés de freqüências ou incidências.

Na perspectiva de Bogdan e Birten (1982), pode-se classificar essa pesquisa como um estudo de caso históricoorganizacional, quando o interesse do pesquisador recai sobre a vida de uma instituição. O pesquisador deve partir do conhecimento que existe a respeito da organização que deseja examinar. Que materiais podem ser remanejados, que estão disponíveis para o pesquisador (ainda que isso represente dificuldades para seu estudo). Significa, segundo os autores, que existem arquivos, publicações, estudos pessoais etc, com os quais é possível realizar entrevistas, análise documental, entre outras.

A utilização do estudo de caso justifica-se quando há a necessidade de uma análise mais profunda dos dados a serem pesquisados. Quando se faz a opção por 
um estudo de caso, seja ele único ou múltiplo, pode ser investigada mais de uma unidade de análise. Quando se deseja estudar uma realidade, o estudo da mesma pode considerá-la como uma totalidade única, de forma global, ou também, pode ser importante considerá-la constituída por uma série de unidades, cuja característica peculiar exige um tratamento diferenciado, isto é, estudo de um caso único, incluindo mais de uma unidade de análise, como é o caso da presente investigação.

No que tange à abordagem qualitativa baseada no desenvolvimento de estudo de caso, existe o risco do estudo limitar-se exclusivamente a uma análise descritiva de processos (superficialidade). Na tentativa de evitar esse risco, Eisenhardt (1989), sugere que não se deve trabalhar com hipóteses, mas pressupostos de pesquisa, amostra teorética e não randômica (focalizar esforço em casos que possam enriquecer a pesquisa proposta - ênfase na qualidade e não na quantidade), e coleta de dados utilizando múltiplos métodos (triangulação).

A técnica de análise documental, igualmente importante na pesquisa qualitativa, deve ser empregada tendo em vista que os documentos são capazes de fornecer um conhecimento mais objetivo da realidade a ser investigada e se constituem numa fonte inesgotável, estável e rica. Po- de-se consultá-los diversas vezes e servem de base para diferentes estudos.

Posição essa corroborada por Ludke e André (1986, p. 39), quando salientam que os documentos representam "ainda uma fonte natural de informação. Não é apenas uma fonte de informação contextualizada, mas surgem num determinado contexto e fornecem informações sobre esse mesmo contexto".

Para Witter (1990, p. 22), a análise documental é "aquela cujos objetivos ou hipóteses podem ser verificados por meio da análise de documentos bibliográficos ou não-bibliográficos, requerendo metodologia (coleta, organização, análise dos dados) compatíveis com os mesmos".

Na opinião de Valentim et al. (2005), a análise documental apresenta o conteúdo de um documento, de forma fiel e sintética, objetivando o estabelecimento da veracidade e posterior consulta.

A técnica do incidente crítico, outro importante recurso metodológico na pesquisa qualitativa, foi formalizada por John C. Flanagan (American Institutes for Research) em 1954. A Técnica do Incidente Crítico (TIC) é um método que consiste num conjunto de procedimentos para obter fatos importantes sobre o comportamento humano em situações definidas.

Essa técnica permite o registro de comportamentos específicos, ou seja, de 
incidentes, que Flanagan (1973, p. 100) assim a define:

qualquer atividade humana observável que seja suficientemente completa em si mesma para permitir inferências e previsões a respeito da pessoa que executa o ato. Para ser crítico um incidente deve ocorrer em uma situação onde o propósito ou a intenção do ato pareça razoavelmente claro ao observador e onde suas conseqüências sejam suficientemente definidas para deixar poucas dúvidas no que se refere aos seus efeitos.

A essência da técnica consiste em solicitar dos sujeitos envolvidos numa atividade, relatos de situações e fatos que são avaliados pelo pesquisador em função da concordância/discordância desses relatos, de acordo com o objetivo e natureza da situação que se deseja estudar.

A técnica de incidente crítico se baseia na teoria de que é mais fácil para as pessoas se lembrarem do que elas fizeram, numa determinada ocasião, do que se lembrarem do que fazem "em geral".

\section{CENÁRIO DA INVESTIGAÇÃO}

O estudo de caso, reitere-se, foi efetuado na Universidade Estadual de Londrina - UEL, Estado do Paraná e teve como foco:

a) os Conselhos Deliberativos Superiores (Conselho Universitário; ConseIho de Administração; Conselho de Ensino, Pesquisa e Extensão e suas Câmaras); b) análise documental de processo ${ }^{1}$ que havia sido concluído em 2004/primeiro trimestre de 2005. A opção pelo referido período deveu-se ao fato da coleta de dados ter se iniciado em abril de 2005. Desta forma, pretendeu-se pesquisar, em profundidade, um processo que tenha sido objeto de deliberação no âmbito dos Conselhos Superiores.

\subsection{Caracterização da Instituição}

A Universidade Estadual de Londrina (UEL) surgiu da junção de cinco faculdades (Faculdade Estadual de Direito de Londrina; Faculdade Estadual de Filosofia, Ciências e Letras de Londrina; Faculdade Estadual de Odontologia de Londrina; Faculdade de Medicina do Norte do Paraná, Faculdade Estadual de Ciências Econômicas e Contábeis de Londrina). É uma instituição de direito público, fundada pelo governo do Estado do Paraná, por meio do Decreto Estadual $n^{\circ} 18.110$, de 28/01/70, sendo reconhecida oficialmente pelo do Decreto Federal $n^{\circ} 69.324 / 71$.

A UEL está localizada em Londrina, Estado do Paraná, sendo a terceira maior cidade do Sul do Brasil, com aproximada-

\footnotetext{
1 Desenvolvimento de um expediente, incluindo tipos diversos de documentos e que, recebendo informações, pareceres e despachos, tramita até que se cumpra o ato administrativo que gerou a sua criação.Unidade documental em que se reúnem oficialmente documentos de natureza diversa, no decurso de uma ação administrativa ou judiciária, formando um conjunto materialmente indivisível. (BELLOTTO, 2004, p. 101).
} 
mente 450.000 habitantes, considerada um pólo regional com influência econômica sobre os municípios localizados no Norte do Estado do Paraná, Sul de São Paulo e Mato Grosso do Sul.

$\mathrm{Na}$ área de ensino, em 2006, a Universidade mantém 42 cursos em nível de graduação (11 na área de Ciências Biológicas e da Saúde; 09 na área de Ciências Exatas e Tecnológicas e, 22 na área de Humanidades). Na pós-graduação, oferta 169 cursos, sendo 95 Lato Sensu, 33 Stricto Sensu (25 em nível de Mestrado e 08 Doutorados), 30 Residências Médicas, 02 Residências em Fisioterapia, 05 em Enfermagem e 04 em Medicina Veterinária. Encontram-se matriculados 14.000 alunos de graduação e 3.129 alunos de pósgraduação.

O corpo docente da instituição é formado por 1.640 professores, sendo 623 doutores (38\%); 658 mestres (40\%), 235 especialistas $(14,4 \%)$ e 124 graduados (7,56\%). No quadro funcional, conta com 3.754 servidores técnico - administrativos distribuídos em várias unidades e subunidades.

$\mathrm{Na}$ área de pesquisa, encontram-se em andamento 873 projetos e 308 grupos de pesquisa, envolvendo 859 docentes e 3.016 discentes. Na extensão, 158 projetos estão cadastrados, englobando aproximadamente 442 docentes e 2.125 alunos e cerca de 150.000 pessoas atendidas na comunidade.

\subsection{Estrutura organizacional}

A estrutura organizacional da Universidade tem como órgãos executivos a Reitoria e 6 (seis) Pró-Reitorias (Graduação, Pesquisa e Pós Graduação, Extensão, Administração e Finanças, Recursos Humanos e Planejamento). São órgãos da Reitoria ainda: Secretaria Geral dos Órgãos Colegiados Superiores, Prefeitura do Campus, Coordenadoria de Processos Seletivos, Coordenadoria de Comunicação Social, Procuradoria Jurídica, Assessoria de Auditoria Interna, Assessoria de Relações Internacionais, Órgãos de Apoio e Órgãos Suplementares.

A UEL, como a maioria das universidades públicas brasileiras, apresenta em sua estrutura organizacional, conselhos superiores de caráter deliberativo, sendo eles: Conselho Universitário, Conselho de Ensino, Pesquisa e Extensão e suas Câmaras, e o Conselho de Administração. Conta ainda com um órgão consultivo denominado Conselho de Interação Universidade-Sociedade.

A UEL possui cinqüenta e seis (56) departamentos distribuídos em nove (9) Centros de Estudos assim discriminados: Centro de Letras e Ciências Humanas; Centro de Ciências Biológicas; Centro de Ciências Exatas; Centro de Estudos Soci- 
ais Aplicados; Centro de Ciências da Saúde; Centro de Educação, Comunicação e Artes; Centro de Ciências Agrárias; Centro de Tecnologia e Urbanismo e Centro de Educação Física e Desportos.

\subsection{Participantes do estudo}

Na pesquisa qualitativa, é indicado o uso de amostra não probabilística, selecionada por critérios subjetivos do pesquisador, de acordo com sua experiência e com objetivos da pesquisa, sendo que esse tipo de amostra consiste em integrar um grupo constituído por sujeitos que proporcionem informação profunda e rica para a investigação. Neste tipo de amostra, utilizou-se a amostra intencional, que consiste em identificar e selecionar uma amostra em que seja possível obter as informações necessárias para o estudo. A lógica e o poder da amostra intencional residem na seleção da informação rica de casos para o estudo em profundidade (MERRIAM, 1998).

Procurou-se, então, investigar os componentes dos Conselhos Superiores Deliberativos que atuam, interferem ou influenciam na Instituição, e que representem tanto a estrutura acadêmica como a administrativa.

No estudo de caso, como afirma Triviños (1987, p. 132), pode-se utilizar a intencionalidade, considerando um rol de condições, tais como "sujeitos que seriam essenciais, segundo o ponto de vista do investigador, para o esclarecimento do assunto em foco; facilidade para encontrar as pessoas; tempo dos indivíduos para as entrevistas etc., o tamanho da amostra".

Desta forma, a intencionalidade constituiu-se nos seguintes critérios:

a. um processo que tenha sido objeto de tomada de decisão por no mínimo dois Conselhos Superiores, visto que se pretende estudar um caso único incluindo mais de uma unidade de análise;

b. um processo que tenha sido analisado o mais recente possível, considerando-se a técnica do incidente crítico, pois, conforme alerta Lancaster (1978), geralmente as pessoas vão se lembrar mais claramente do último incidente de um tipo particular, esse último evento torna-se o "incidente crítico";

c. conselheiros que tenham participado das reuniões nas quais o processo selecionado foi analisado e deliberado, pois se acredita que as pessoas que participaram diretamente de um determinado evento possam contribuir mais com o estudo em questão (técnica do incidente crítico);

d. Representação de categorias nos Conselhos Superiores:

I Reitor 
II Conselho de Ensino, Pesquisa e Extensão;

III Conselho de Administração;

IV Pró-reitores, principalmente ligados às áreas de planejamento e finanças, recursos humanos e ensino (graduação e pós-graduação);

V Docente dos Centros de Estudos da Universidade sem vínculo a qualquer instância administrativa;

VI Docente que represente uma das classes de Professor Auxiliar, Professor Assistente, Professor Adjunto, Professor Associado e Professor Titular;

VII Servidores técnico-administrativos;

VIII Discentes.

e. tempo de serviço na Universidade Estadual de Londrina para a seleção dos conselheiros dentro de uma mesma categoria (aplicados aos incisos $\mathrm{V}$ a VII), e para o inciso VIII, o tempo de representação dos discentes nos Conselhos Superiores, pois, no entender da pesquisadora, a experiência adquirida com o tempo, na academia, muito contribuirá para o resultado da investigação.

Para a escolha dos sujeitos, utilizouse como referência as recomendações de Minayo (2000), quando afirma que uma amostra ideal é aquela que privilegia os sujeitos sociais que detêm os atributos que se pretende conhecer, ou seja, aquela que, por meio de um número suficiente de entrevistas, fornece informações relevantes que conduzam à formulação de categorias e que seja capaz de refletir a totalidade nas suas dimensões.

Considerando os critérios elencados e as informações que os Conselheiros dispunham em torno do tema proposto, a amostra intencional ficou assim distribuída:

\section{a) Conselho Universitário}

- Reitor

- Três (3) Pró-Reitores (Planejamento, Recursos Humanos, Graduação)

- Dois (2) Representantes do ConseIho de Ensino, Pesquisa e Extensão.

- Um (1) Representante docente dos Centros de Estudos não vinculado a qualquer instância administrativa

- Um (1) Representante da categoria docente (auxiliar de ensino, assistente, adjunto, associado e titular)

- Um (1) Representante da categoria discente

- Um (1) Representante dos servidores técnico-administrativos

\section{b) Conselho de Administração}

- 09 Diretores de Centro de Estudos 
- 01 Representante discente

- 01 Representante dos servidores técnico-administrativos.

É preciso registrar que um dos membros do Conselho Universitário recusou-se a tomar parte do estudo, embora tenha sido informado da importância de sua participação e da pesquisa.

Foram excluídos da amostra os representantes do Conselho Universitário externos à Instituição, uma vez que eles, segundo a visão da pesquisadora, não teriam contribuição significativa, considerando-se os objetivos do estudo.

O processo selecionado permitiu, ainda, identificar seis (6) servidores (um docente e 5 técnico-administrativos), em cada uma das unidades e subunidades da Instituição, que foram os responsáveis pelas informações anotadas no mesmo.

Assim sendo, os participantes do estudo totalizaram vinte e seis (26), sendo vinte (20) dos Conselhos Deliberativos Superiores (11 membros do Conselho de Administração e 9 membros do Conselho Universitário) e seis (6) servidores que registraram as informações no processo 22.389/2004. Embora todos os sujeitos sejam considerados atores do processo, para efeito de distinção dos mesmos, utilizou-se a terminologia de "atores do processo" para os servidores identificados pelas respectivas assinaturas no processo analisado, os quais foram caracterizados nas entrevistas pela letra A. Os membros dos Conselhos Deliberativos Superiores foram qualificados como "decisores", sendo identificados nas entrevistas pela letra D.

\section{COLETA DE DADOS}

De acordo com Martucci (1996), "a coleta de dados qualitativos ocorre por meio de um contato profundo com uma pequena amostra de sujeitos".

Como instrumentos de coleta de dados foram utilizados o formulário e entrevista semi-estruturada. O formulário teve como alvo identificar as informações, verificando a natureza das mesmas.

A entrevista semi-estruturada "valoriza a presença do investigador, oferece todas as perspectivas possíveis para que 0 informante alcance a liberdade e a espontaneidade necessárias, enriquecendo a investigação." (TRIVIÑOS, 1987, p. 146).

$\mathrm{Na}$ coleta de dados, utilizou-se um enfoque triangular composto por análise documental, aplicação de entrevista com roteiro semi-estruturado e a técnica do incidente crítico. Optou-se pela multiplicidade de métodos, pois permite, ao mesmo tempo, comparar as respostas levantadas com base na percepção de diferentes pessoas que pertencem à instituição. 
A coleta de dados foi realizada em três etapas, que são descritas a seguir.

\subsection{Análise documental}

Foram consultadas todas as atas ${ }^{2}$ das reuniões ordinárias e extraordinárias dos Conselhos Deliberativos Superiores no período de 2004 ao primeiro trimestre de 2005, buscando identificar um processo que tivesse sido analisado e deliberado por, no mínimo dois Conselhos, e que fosse o mais recente possível, visto que, como já foi apresentado, na adoção da técnica do incidente crítico, os dados coletados devem ser recentes para evitar lapsos de memória dos informantes.

Assim, selecionou-se o Processo 22.389/04 - Reestruturação da Coordenadoria de Comunicação Social (COM), analisado pelo Conselho de Administração em 25 de agosto de 2004 e pelo Conselho Universitário em 18 de fevereiro de 2005.

A cópia integral de todo o processo foi obtida junto à Divisão de Comunicação e Arquivo da Universidade. As informações contidas, neste processo, foram agrupadas e analisadas, minuciosamente, à luz do referencial teórico adotado.

Deve-se esclarecer que um determinado processo, depois de formalizado,

\footnotetext{
${ }^{2}$ As atas são criadas no contexto das atividades colegiadas de decisão e no exercício da ação do poder representativo na universidade, implicando ou exigindo a aprovação de pessoas oficialmente reunidas (GAGNON-ARGUIN; VIEN, p. 67, 1999).
}

tramita por todas as unidades e subunidades da Instituição, para ser instruído, ou seja, provido de informações, para que, ao serem analisados pelos Conselhos Deliberativos Superiores, esteja com todas as informações necessárias e com parecer $^{3}$ da Procuradoria Jurídica da Instituição. Quando ainda persistir alguma dúvida, geralmente, o processo é retirado de pauta e retorna para complementação das informações para então, novamente, ser objeto de análise e decisão.

\subsection{Estudo piloto}

Nas pesquisas qualitativas, 0 instrumento de coleta de dados denominado "roteiro de entrevista" deve sofrer modificações sucessivas, em decorrência da aplicação do estudo piloto.

O estudo piloto permite ao investigador esclarecer áreas de conteúdo não delimitadas do todo nas primeiras etapas, comprovar as adequações das questões norteadoras, descobrir novos aspectos que não foram contemplados inicialmente.

Para o desenvolvimento das entrevistas, foram elaborados dois roteiros (decisores e atores do processo) com questões norteadoras, sendo aplicadas aleatoriamente a cinco pessoas, sendo três (3) conselheiros, que atuaram, mas não participam nesta gestão dos Conselhos Delibera-

\footnotetext{
${ }^{3}$ Parecer é um documento de opinião técnica ou científica sobre um ato, servindo de base para a tomada de decisão. (BELLOTTO, 2004, p. 100).
} 
tivos Superiores, e dois (2) servidores técnico-administrativos (docente ou funcionário) das Pró-Reitorias que normalmente instruem os processos e não tiveram atuação no processo 22.389/04.

Assim, foram testadas as questões do roteiro-piloto, na segunda quinzena de abril de 2005, quando se observou a pertinência e as adequações das questões aos objetivos da pesquisa.

\subsection{Entrevistas}

As entrevistas foram realizadas em duas fases, na primeira com os decisores e na segunda com os atores do processo selecionado. A opção pela entrevista com roteiro semi-estruturado deve-se ao fato de que ela permite criar um ambiente propício, no qual os entrevistados podem discorrer livremente a respeito de seus pontos de vista.

A pesquisadora seguiu um breve roteiro com questões norteadoras, não com a intenção de padronizar as perguntas, mas para garantir que determinado questionamento fosse exposto a todos os sujeitos do estudo. Como bem salientam Ludke e André (1986), é preferível e mesmo aconseIhável o uso de um roteiro que guie a entrevista pelos tópicos principais a serem abordados.

As questões estavam dispostas numa configuração próxima a uma conversa informal, de forma a permitir a expressão livre, com o objetivo de deixar o entrevistado à vontade para declarar suas opiniões.

As entrevistas foram realizadas no período de maio até a primeira quinzena de julho de 2005. O roteiro da entrevista foi planejado para conduzir uma conversa por aproximadamente 40 minutos. Todas foram gravadas com a permissão dos participantes e posteriormente transcritas para análise. Foi assegurado o anonimato aos sujeitos da investigação. A gravação utilizada como recurso para a investigação impede a perda de detalhes, a desaleceração do ritmo de conversação e o efeito sobre a espontaneidade e fluidez do informante. (VALLES, 1997).

Para a identificação dos decisores foram consultados alguns documentos oficiais na Secretaria Geral dos Órgãos Colegiados Superiores (SGOCS). Essa Unidade encontra-se diretamente subordinada ao Reitor, cuja competência é dar apoio administrativo e logístico na condução e execução dos trabalhos concernentes a todos os Conselhos Superiores. O acervo da SGOCS é composto basicamente por documentos textuais (Resoluções, Atas, Portarias, Atos Executivos entre outros), fitas k-7 nas quais são gravadas as reuniões dos Conselhos e disquetes com as atas efetuadas. Os documentos consultados compreenderam:

a) Estatuto da Universidade Estadual de Londrina; 
b) Atas das reuniões número 926 de 25 de agosto de 2004 do Conselho de Administração, e reunião número 419 de 18 de fevereiro de 2005 do Conselho Universitário, na qual foi discutido o referido processo;

c) Lista de presença dos conselheiros às referidas reuniões;

d) Portaria de nomeações dos atuais conselheiros, o que permitiu identificar a categoria de representação;

e) Portaria de nomeação para o cargo (servidores, docentes e técnicos administrativos), obtida junto à Pró-Reitoria de Recursos Humanos, identificando a data de admissão dos conselheiros, quando houve mais de um representante da mesma categoria presente às citadas reuniões,

f) Portaria de nomeações dos discentes, nos últimos quatro anos de representação nos Conselhos Superiores, para identificar o tempo de representação desta categoria, quando houve mais de um representante presente às reuniões mencionadas.

Em relação aos atores do processo, a identificação foi pelo nome/assinatura e unidade/subunidade constante no referido processo.

Identificados todos os participantes da investigação, o caminho percorrido para a realização das entrevistas compreendeu os seguintes passos:
1. contato via e-mail com todos os sujeitos escolhidos, apresentando os objetivos da pesquisa e informando que eles seriam contatados via telefone, posteriormente, para agendamento das entrevistas;

2. agendamento por telefone, deixando por conta do entrevistado a escolha da data, horário e local, já que era importante deixá-lo à vontade;

3. apresentação dos objetivos do estudo e outras informações que permitissem situar os participantes sobre o tipo de informações que se buscava colher;

4. solicitação de autorização prévia para se gravar as entrevistas, objetivando assegurar a possibilidade de recuperação das informações durante o procedimento da análise,

5. transcrição de todas as entrevistas, nas quais, para controle, os sujeitos foram identificados por categoria (decisores ou atores do processo) e dentro desta por numeração seqüencial agregado a letra de sua categoria, ou seja, a letra D para decisores e a letra A para os atores do processo.

A interpretação das entrevistas foi efetuada mediante a técnica de análise de conteúdo (BARDIN, c1977), por meio da qual foi atribuída relevância aos comentários diretos extraídos das entrevistas, considerando-se as palavras empregadas e os seus significados, o contexto em que foram 
colocadas as idéias, a freqüência, a extensão dos comentários e a especificidade das respostas.

\section{TRATAMENTO E ANÁLISE DOS DADOS}

Na pesquisa qualitativa, a análise dos dados não é a última fase do processo, ou seja, ela é concomitante à coleta de dados ou é cíclica.

Os pesquisadores costumam encontrar três grandes obstáculos quando iniciam a análise dos dados recolhidos no campo "[...] O primeiro deles [...] 'ilusão da transparência' [...] O segundo [...] sucumbir à magia dos métodos e das técnicas [...] $\mathrm{O}$ terceiro [...] é a dificuldade de se juntarem teorias e conceitos muito abstratos com os dados recolhidos no campo" (MINAYO, 2000, p. 197).

De acordo com Patton (1987), a análise dos dados qualitativos é um processo criativo que demanda rigor intelectual, possui uma grande quantidade de dificuldades e é um trabalho muito cuidadoso, pois as diferentes pessoas dirigem sua criatividade, seu esforço intelectual e seu trabalho de modos diferentes, não existindo apenas uma forma correta para organizar, analisar e interpretar dados qualitativos.

A análise de conteúdo é uma estratégia de pesquisa utilizada no intuito de tornar objetivo o conteúdo dos dados coleta- dos na investigação. Esta análise pode ser entendida como um conjunto de técnicas de análise de comunicação, visando, por procedimentos sistemáticos e objetivos de descrição do conteúdo das mensagens, obter indicadores quantitativos ou não, que permitam a inferência de conhecimentos relativos às condições de produção/recepção (variáveis inferidas) das mensagens (BARDIN, c1977).

Com essa técnica, é possível analisar as "entrelinhas das opiniões das pessoas, não se restringindo unicamente às palavras expressas diretamente, mas também àquelas que estão subentendidas no discurso, fala ou resposta de um respondente" (PERRIEN; CHÉRON; ZINS, 1984, p. 27).

Para efetuar a análise de conteúdo, utilizou-se a técnica de análise categorial (ou temática), pois se tratava do "desmembramento do discurso em categorias, em que os critérios de escolha e de delimitação orientam-se pela dimensão da investigação dos temas relacionados ao objeto de pesquisa, identificados nos discursos dos sujeitos pesquisados" (BARDIN, c1977, p. 80-81).

Nos dados apresentados em tabelas, também foi incluída a análise quantitativa (freqüência) das categorias estabelecidas. Isto foi possível porque se acredita que "a análise de conteúdo atua, portanto, combinando técnicas com características quantitativa e qualitativa, com o fim de obter mai- 
or riqueza de detalhes do objeto/fenômeno pesquisado" (VALENTIM et al., 2005, p. 133).

As categorias de análise de conteúdo determinadas a posteriori compreenderam:

1.Procedimentos adotados para instrução dos processos (informações) para a decisão dos Conselhos Deliberativos Superiores;

2. Características das informações mais utilizadas para instruir/ informar os processos;

3. Forma de organização das fontes mais utilizadas/consultadas;

4. Elementos facilitadores na obtenção/recuperação das informações;

5. Elementos dificultadores na obtenção/recuperação das informações;

6. Recebimento das informações necessárias para a tomada de decisão nos processos em pauta das reuniões dos Conselhos Superiores;

7. Características das informações mais utilizadas e imprescindíveis para a tomada de decisão;

8. Forma de obtenção/recuperação das informações que necessita para a tomada de decisão;

9. Solicita informações antes de tomar decisões;
10.Informações constantes do processo 22.389/04 para a tomada de decisão.

\subsection{Organização dos dados para análise}

As fases da análise de conteúdo organizaram-se cronologicamente em: préanálise, análise do material, tratamento dos resultados, inferência e interpretação.

Pré-análise é a fase da organização e sistematização das idéias, em que ocorre a escolha dos documentos a serem analisados; a retomada dos pressupostos e dos objetivos iniciais da pesquisa em relação ao material coletado, e a elaboração de indicadores que orientarão a interpretação final.

Essa fase engloba quatro etapas: a leitura flutuante, na qual deve haver um contato exaustivo com o material de análise; constituição do corpus, que envolve a organização do material de forma a responder a critérios de exaustividade (contemplando todos os aspectos levantados no roteiro); representatividade (contendo a representação do universo pretendido); homogeneidade (obedecendo a critérios precisos de escolha, em termos de temas, técnicas e interlocutores); pertinência (os materiais analisados devem ser adequados aos objetivos do estudo); formulação de hipóteses e objetivos iniciais flexíveis que permitam a emergência de hipóteses a partir de procedimentos exploratórios; referen- 
ciação dos índices, elaboração de indicadores a serem adotados na análise e preparação do material.

A fase de análise do material consiste essencialmente na operação de codificação, transformando os dados brutos em dados que consigam alcançar o núcleo de compreensão do texto. A codificação é um processo pelo qual os dados brutos são, sistematicamente, transformados e agrupados em unidades que permitem uma descrição exata das características relevantes do conteúdo. Desta forma, a codificação é uma transformação que segue regras específicas para os dados de um texto. Envolve procedimentos de recorte, contagem, classificação ou enumeração em função de regras previamente estabelecidas na pré-análise. $\mathrm{Na}$ investigação da tese, utilizou--se frases ou fragmentos de frases, nesse processo de corte e recortes do conteúdo das falas dos decisores e dos atores do processo.

No tratamento dos resultados, inferência e interpretação, os dados brutos foram submetidos a operações de codificação e categorização, o conteúdo codificado foi traduzido em informações relevantes que exprimem o significado daquele conteúdo para o objeto de investigação. Após o tratamento, passou-se à fase de interpretação e inferência sobre os mesmos. É um momento de forte trabalho intelectual em que o pesquisador propõe suas inferências e realiza interpretações de acordo com o referencial teórico, os objetivos e os pressupostos do estudo, ou identifica novas dimensões teóricas sugeridas pela leitura do material.

Conforme Franco (2003, p. 25), se a descrição (enumeração das características do texto, resumida após tratamento inicial) é a primeira etapa necessária e se a interpretação (significação concedida a essas características) é a última fase, "a inferência é o processo intermediário que vai permitir a passagem explícita e controlada da descrição à interpretação".

Uma vez estando o universo claramente definido, inicia-se o processo de categorização e determinação das dimensões que serão analisadas, que irão definir a teia da grade de análise. No estudo que deu origem à tese, as categorias não foram definidas a priori, ou seja, as categorias emergiram das falas, do conteúdo das respostas dos sujeitos e implicaram uma constante ida e volta do material de análise à teoria, isso graças a flexibilidade da pesquisa qualitativa.. Optou-se pela elaboração de um sistema categórico nãoapriorístico, pois se considerou a possibilidade de obtenção de dados novos e diversificados que poderiam surgir.

Para a criação das categorias devese observar alguns princípios, tais como: 
a)exclusão mútua - cada elemento não pode existir em mais de uma divisão. Um único principio de classificação deve orientar a sua organização;

b) pertinência - a categoria deve se adaptar ao material de análise escolhido e ao quadro teórico definido,

c) objetividade e fidelidade - as diferentes partes de um mesmo material, ao qual se aplica uma determinada categoria, devem ser codificadas da mesma maneira, mesmo quando submetidas a várias análises.

O processo de análise de conteúdo "tem início com a decisão sobre a unidade de análise" (LUDKE; ANDRÉ, 1986, p. 41), o que pode ser encarada, segundo Holsti (1969) como uma unidade de registro (todo o excerto de texto que isoladamente seja pertinente); como uma unidade de contexto (a própria entrevista), dependendo a escoIha do método de codificação, "da natureza do problema, do arcabouço teórico e das questões específicas da pesquisa”.(LUDKE; ANDRÉ, 1986, p. 42).

Para a construção das categorias, foi efetuada uma leitura preliminar e várias releituras das entrevistas, o que resultou numa categorização inicial. Após esse processo, efetuaram-se as leituras verticais de cada uma das entrevistas realizadas, seguida das leituras horizontais do conjunto das entrevistas, o que permitiu pensar e repensar o sistema de categorização a ser adotado, não perdendo de vista os objetivos e o referencial teórico da investigação. Lembrando que a categorização dos incidentes críticos, de acordo com Estrela e Estrela (1994), também encerra a mesma dificuldade e obedece aos mesmos critérios que qualquer análise de conteúdo.

Essa fase de categorização implicou o agrupamento e reagrupamento do material idêntico, decorrendo as categorias em função do significado dos indicadores, num processo constante de definição, redefinição e comparação (LUDKE; ANDRÉ, 1986), procurando que sua validade fosse assegurada por critérios de homogeneidade, coerência, exclusividade recíproca e exaustividade. (BARDIN, c1977; LUDKE; ANDRÉ, 1986).

Findo esse processo, fez-se, outra vez, uma leitura mais minuciosa das entrevistas codificadas e categorizadas, o que possibilitou analisá-las integralmente e efetuar algumas alterações que se consideravam necessárias.

\section{CONSIDERAÇÕES FINAIS}

Os procedimentos metodológicos se constituem nas explicações minuciosas, detalhadas e precisas de todas as ações empreendidas no percurso da investigação. 
É preciso compreender que a trajetória metodológica planejada previamente para o desenvolvimento da pesquisa nem sempre ocorre como programado, mas vai sendo delineada durante todo o processo de investigação, exigindo, assim, a flexibilização do pesquisador.

A tendência hoje parece ser a de combinar diferentes métodos e instrumentos de pesquisa. Entretanto, o mais importante é a objetividade e a consistência teórica com a busca de rigor em todo o desenvolvimento da pesquisa.

O caminho percorrido neste relato de experiência também não foi diferente. Foram muitas idas e vindas à procura de um melhor procedimento metodológico tendo em vista os objetivos da investigação.

Para a tese, os procedimentos metodológicos adotados, mostraram-se satisfatórios e adequados para atingir os objetivos propostos.

Assim, espera-se ter contribuído de alguma forma no fornecimento de um exemplo de procedimentos metodológicos aplicados em uma investigação.

\section{REFERÊNCIAS}

BARDIN, L. Análise de conteúdo. Lisboa: Gráfica Telles da Silva, c1977.

BELLOTTO, H. L. Arquivos permanentes: tratamento documental. 2.ed. rev. ampl. Rio de Janeiro: FGV, 2004.
BENBASAT, I.; GOLDSTEIN, D. K.; MEAD, $M$. The case research strategy in studies of information systems. MIS Quarterly, n. 4, p. 368-386, 1987.

BOGDAN, R. C.; BIRTEN, S. K. Qualitative research for education: an introduction for to theory and methods. Boston: Allyn and Bacon, 1982.

DENZIN, N. K.; LINCOLN, Y. S. (Ed.). Strategies of qualitative inquiry. London: Sage Publications, 1998.

EISENHARDT, K. M. Building theories from case study research. Academy of Management Review, v. 14, n. 4, p. 532-550, 1989.

ESTRELA, M. T. ; ESTRELA, A. A. A técnica dos incidentes críticos no ensino. 2.ed. Lisboa: Estampa, 1994.

FLANAGAN, J. C. A técnica do incidente crítico. Arquivo Brasileiros de Psicologia Aplicada, Rio de Janeiro, v. 25, n. 2, p. 99141, abr./jun. 1973.

FRANCO, M. L. P. B. Análise de conteúdo. Brasília: Plano, 2003.

GAGNON-ARGUIN, L. ; VIEN, H.

Typolopgie des documents des organizations. Quebec: Université du Quebec, 1999.

GRAMSCI, A. Cadernos do cárcere. Rio de Janeiro: Civilização Brasileira, 1999. v.1.

HOLSTI, O. Content analysis for the social sciences and humanities. Boston: Addison Wesley, 1969.

LANCASTER, F. W. Critical incident techniques. Urbana: University of Illinois Graduate School of Library Science, 1978.

LIEBSCHER, P. Quantily with quality? teaching quantitative and qualitative methods in a LIS Master's program. Library Trends, v. 46, n. 4, p. 668-80, Spring, 1998. 
LUDKE, M.; ANDRÉ, M. E. D. A. Pesquisa em educação: abordagens qualitativas. São Paulo: EPU, 1986.

MARTUCCI, E. M. Abordagem qualitativa de pesquisa em Biblioteconomia: uma introdução. São Paulo: APB, 1996. (Ensaios APB, n. 33).

MERRIAM, S. Qualitative research and case study applis in education. San Francisco: Jossey-Bass, 1998.

MINAYO, M. C. de S. Pesquisa social teoria, método e criatividade. Petropólis: Vozes, 1997.

O desafio do conhecimento científico: pesquisa qualitativa em saúde. 7 . ed. São Paulo: Hucitec, 2000.

PATTON, P. Q. How to use qualitative methods in evaluation. Newbury: Sage, 1987.

PERRIEN, J.; CHÉRON, E. J. ; ZINS, M. Recherche en marketing: méthodes et décisions. Québec : Gaetan Morin, 1984.

STRAUSS, A.; CORBIN, J. Basics of qualitative research: grounded theory procedures and techniques. Londres: Sage, 1990.

TRAUTH, E. M.; OCONNOR, B. A study of the interaction between information technology and society: an illustration of combined qualitative research methods. Disponível em:

$<$ http://www.cba.neu.edu/ etrauth/works/ifi p5.txt.> Acesso em: 27 jul. 2005.

TRIVIÑOS, A.N.S. Introdução à pesquisa em Ciências Sociais: a pesquisa qualitativa em educação. São Paulo: Atlas, 1987.

VALENTIM, M. L. P. et al. Pesquisa em inteligência competitiva organizacional: utilizando a análise de conteúdo para a coleta e análise de dados. Parte II. Transinformação, Campinas, v. 17, n. 3, p. 253270, set./dez. 2005.
VALLES, M. Técnicas cualitativas de intervencíon social: reflexíon, metodologia y práctica profesional. Madrid: Sintesis, 1997.

WITTER, G. P. Pesquisa bibliográfica, pesquisa documental e busca de informação. Estudos de Psicologia, Campinas, v. 7, n. 1, p. 5-30, jan. /jun. 1990.

Nádina Aparecida Moreno

Professora Adjunto do Departamento de Ciência da Informação da UEL. Doutora em Ciência da Informação (UFMG) nadina@uel.br

\section{Title}

The archivist information in the decision-making process in university institutions: methodological procedures

\section{Abstract}

Reports the methodological trajectory of the doctor thesis titled "The archivist information in the decision-making process in university institutions". The study had a qualitative approach, which adopted a case study, the documental analysis and Flanagan's critical incident technique (1973). The case study was conducted in the Superior Council of the State University of Londrina, Parana State. The documental analysis was carried out in a particular process of the institution, according to the intentionality criteria developed by the researcher. Halfstructured interviews were taken with the research participants and the Bardin's content analysis technique (c1977) was applied to analyze the results. The methodological procedures selected were considered suitable for the research purpose and made possible to achieve its objectives.

\section{Keywords}

Archivist Information, University Institutions 


\section{Titulo}

La información archivística en el proceso de tomada de decisión en organizaciones universitarias: procedimientos metodológicos

\section{Resumen}

Relata la trayectória metodológica recorrida en la tesis de postgrado con el título "la información archivística en el proceso de tomada de decisión en organizaciones universitarias". El abordaje seleccionado fue cualitativo, donde se adoptó el estudio de caso, el análisis documental y la técnica del incidente crítico de Flanagan (1973). El estudio de caso fue efectuado junto a los Consejos Superiores de la Universidad Estatal de Londrina, Estado (Provincia) de Paraná. El análisis documental se efectivó en un determinado proceso de la Institución, de acuerdo con los critérios de intencionalidad elaborados por la investigadora. Las citas con los sujetos del estudio fueron semiestructurados y se utilizó el análisis del contenido de Bardin (c1977). Los procedimientos metodológicos seleccionados en la investigación fueron adecuados y permitieron atingir los objetivos propuestos.

\section{Palabras Clave}

Información Archivística; Organizaciones Universitárias.

Recebido em: 01.12.2006

Aceito em: 10.01.2007 